\title{
RNA-Seq analysis of the multipartite genome of Rhizobium etli CE3 shows different replicon contributions under heat and saline shock
}

\author{
Gamaliel López-Leal ${ }^{*}$, Maria Luisa Tabche², Santiago Castillo-Ramírez ${ }^{1}$, Alfredo Mendoza-Vargas³, \\ Miguel A Ramírez-Romero ${ }^{4^{*}}$ and Guillermo Dávila ${ }^{1}$
}

\begin{abstract}
Background: Regulation of transcription is essential for any organism and Rhizobium etli (a multi-replicon, nitrogen-fixing symbiotic bacterium) is no exception. This bacterium is commonly found in the rhizosphere (free-living) or inside of root-nodules of the common bean (Phaseolus vulgaris) in a symbiotic relationship. Abiotic stresses, such as high soil temperatures and salinity, compromise the genetic stability of $R$. etli and therefore its symbiotic interaction with $P$. vulgaris. However, it is still unclear which genes are up- or down-regulated to cope with these stress conditions. The aim of this study was to identify the genes and non-coding RNAs (ncRNAs) that are differentially expressed under heat and saline shock, as well as the promoter regions of the up-regulated loci.
\end{abstract}

Results: Analysing the heat and saline shock responses of R. etli CE3 through RNA-Seq, we identified 756 and 392 differentially expressed genes, respectively, and 106 were up-regulated under both conditions. Notably, the set of genes over-expressed under either condition was preferentially encoded on plasmids, although this observation was more significant for the heat shock response. In contrast, during either saline shock or heat shock, the down-regulated genes were principally chromosomally encoded. Our functional analysis shows that genes encoding chaperone proteins were up-regulated during the heat shock response, whereas genes involved in the metabolism of compatible solutes were up-regulated following saline shock. Furthermore, we identified thirteen and nine ncRNAs that were differentially expressed under heat and saline shock, respectively, as well as eleven ncRNAs that had not been previously identified. Finally, using an in silico analysis, we studied the promoter motifs in all of the non-coding regions associated with the genes and ncRNAs up-regulated under both conditions.

Conclusions: Our data suggest that the replicon contribution is different for different stress responses and that the heat shock response is more complex than the saline shock response. In general, this work exemplifies how strategies that not only consider differentially regulated genes but also regulatory elements of the stress response provide a more comprehensive view of bacterial gene regulation.

\section{Background}

In eubacteria, a primary strategy for gene regulation is the modulation of transcriptional initiation [1-3]. This is typically controlled by an RNA polymerase, along with its sigma factors, and can be modified (positively or negatively) by transcription factors (TFs) [3,4]. The number of

\footnotetext{
* Correspondence: gamlopez@ccg.unam.mx; ma.ramirez.romero@gmail.com

'Programa de Genómica Evolutiva, Centro de Ciencias Genómicas,

Universidad Nacional Autónoma de México, Apartado Postal 565-A,

Cuernavaca, Morelos C.P 62210, México

${ }^{4}$ Oncomedic. Cuauhtémoc 84A, Col, Torrielo Guerra, México, DF C.P. 14050, México

Full list of author information is available at the end of the article
}

sigma factors and TFs encoded in a given genome varies across bacterial species [5]. Usually, bacteria with large genomes have numerous sigma factors and TFs [6], suggesting a positive correlation between genome size and the content of transcriptional regulators. This observation also applies to the bacterial lifestyle, as large genome-sized species usually dominate in environments where resources are scarce and conditions fluctuate, such as in soil $[7,8]$. The use of specific sigma factors and numerous TFs ensures a very specific promoter recognition and highly gene-specific transcriptional control [9-11].

\section{Biomed Central}

(c) 2014 López-Leal et al.; licensee BioMed Central Ltd. This is an Open Access article distributed under the terms of the Creative Commons Attribution License (http://creativecommons.org/licenses/by/4.0), which permits unrestricted use, distribution, and reproduction in any medium, provided the original work is properly credited. The Creative Commons Public Domain Dedication waiver (http://creativecommons.org/publicdomain/zero/1.0/) applies to the data made available in this article, unless otherwise stated. 
Additionally, small RNA transcripts (typically 50$350 \mathrm{nt}$ ), which are not translated into proteins, have recently been identified as key elements that regulate the bacterial stress response [12], pathogenicity and other cellular processes, for example; chromosomal replication, cell division [13], RNA processing [14] and protein stability [15]. These small transcripts are a heterologous group of molecules that can act by base-pairing to mRNAs to modify translation efficiency and the stability of the mRNA (via degradation) [16] or by binding to proteins to modify their activities. In plant symbiotic bacteria, several computational predictions and experimental studies have been conducted to identify and characterize these elements $[17,18]$. However, despite those efforts to identify novel ncRNAs, the characterization and identification of ncRNA targets is still a rather unexplored subject [19].

Rhizobium etli is a soil bacterium that can associate with the roots of the common bean (P. vulgaris) [20]. These bacteria are able to establish a symbiotic relationship with legumes; in such a relationship, the formation of root nodules is induced and the $R$. etli in these nodules differentiates into nitrogen-fixing bacteroide [20]. These bacteroides convert dinitrogen into ammonium, which the plant uses as a nitrogen source. Similar to the genomes of soil-living bacteria, $R$. etli shows high levels of genome plasticity and genome redundancy, which is reflected in the number of sigma factors. In this regard, $R$. etli encodes twenty-three sigma factors, a housekeeping gene $\sigma^{70}(\operatorname{sig} A)$, two $\sigma^{54}\left(\right.$ rpoN), two $\sigma^{32}(r p o H)$ and 18 extracellular factor (ECF) genes. This sigma factor redundancy is also present in other Rhizobia; for instance Bradyrhizobium japonicum has 26 sigma factors, Mesorhizobium loti encodes 25 and Sinorhizobium meliloti contains 16 sigma factors [21-24]. To the contrary, very little is known about the ncRNAs in $R$. etli.

In the rhizosphere, bacteria are exposed to the adverse effects that result from changes in salinity and temperature [25], thus affecting the survival of Rhizobium in the soil as well as the initial steps of symbiosis $[25,26]$. Here, to further characterise the heat and salt shock responses, we explore the transcriptomic response of $R$. etli CE3 by RNA-Seq following heat (30 minutes at $42^{\circ} \mathrm{C}$ ) and saline shocks (30 minutes in $80 \mathrm{mM} \mathrm{NaCl}$ ). The first aim of this study was to identify genes that are differentially expressed under these stresses; additionally, we studied the ncRNAs and the promoter regions of the up-regulated genes. In doing so, we gained new insights into the global response of $R$. etli under both stress conditions. Our results indicate that replicon contribution is different for different stress responses; furthermore, it seems that the heat shock response is more complex compared to the saline shock response.

\section{Results}

\section{Identifying the differentially expressed genes}

To identify which genes are expressed following either heat shock or saline shock, nine RNA-Seq libraries were generated from Rhizobium etli CE3 growth in three different conditions: reference, heat shock and saline shock (see Methods). Three biological and independent experiments were performed for each condition; the general features of the results from each run are shown in Additional file 1. The libraries were sequenced and 15-50 million reads were obtained under the control condition, 16-53 million under heat shock and 16-53 million under saline shock. These numbers indicate that similar amounts of data were generated for the different conditions considered here. The Bowtie tool was used to map the reads to the annotated $R$. etli CFN42 genome (see Methods). An average of $4,877,844.67$ (+/ - 1,792,644.23) reads could be unambiguously mapped for the reference condition, 3,840,059 $(+/-1,208,900.91)$ for the heat shock condition, and $4,312,365.33(+/-2,340,976.94)$ for the saline shock condition (Additional file 1); as with the data generated, similar amounts of data could be mapped for each condition. Because these data were used in downstream analyses, we validated the data set by performing quantitative reverse transcription PCR (qRT-PCR) of twenty-seven genes selected from the RNA-Seq analysis (Additional file 2). We noted a high degree of correlation $(R=0.97)$ between the $\log 2$-transformed values of the quantification cycles $(\mathrm{Cp})$ and the $\log 2$-transformed RPKM from the RNA-Seq data.

A previous study showed that the $R$. etli genome has 5963 genes distributed across one chromosome and six large plasmids [20], to identify which of those are differentially expressed under each stress condition, a nonparametric approach was applied to the RNA-Seq data using NOISeq. The differential expression analysis revealed 756 differentially expressed genes $(12.67 \%$ of the total) under heat shock conditions. Of these, 446 and 310 were up-regulated and down-regulated, respectively. Under saline shock conditions, we identified 392 (6.57\%) differentially expressed genes. Of these, 208 and 184 were up-regulated and down-regulated, respectively. Among the total number of up-regulated genes, 340 were specific to heat shock, 102 were specific to saline shock and 106 were up-regulated under both conditions (Figure 1). Considering the total number of down-regulated genes, 254 were specific to heat shock, 128 were specific to saline shock and 56 were downregulated under both conditions. These results suggest that the response to heat shock could be more complex because the number of differentially expressed genes following heat shock was twice the number observed following saline shock. To determine if these differentially expressed genes were homogeneously distributed 


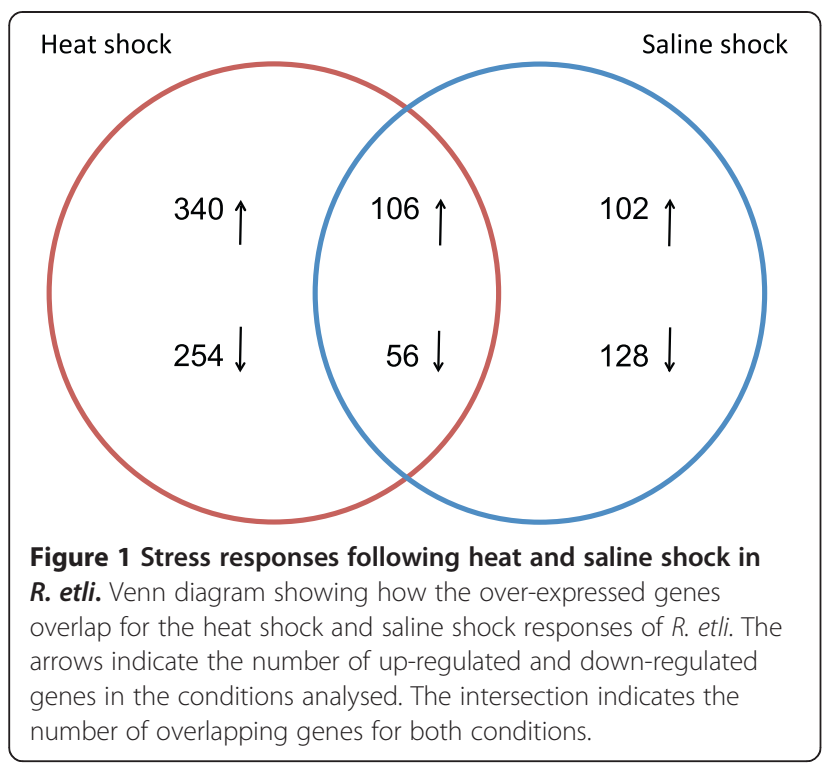

A)

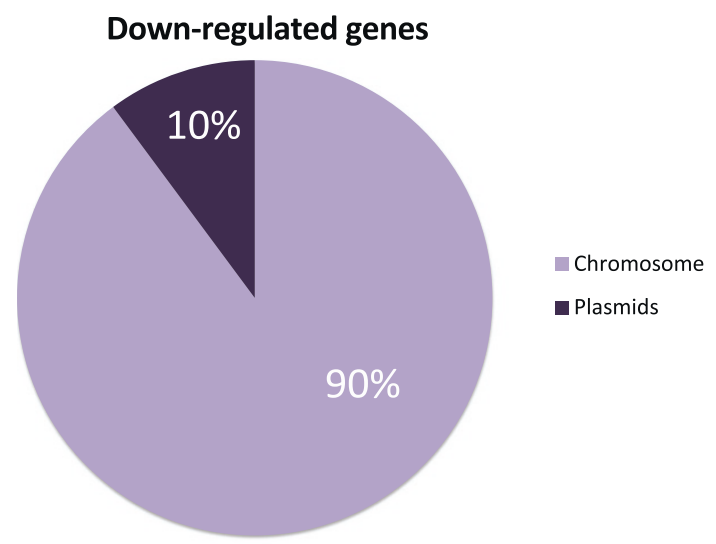

Up-regulated genes

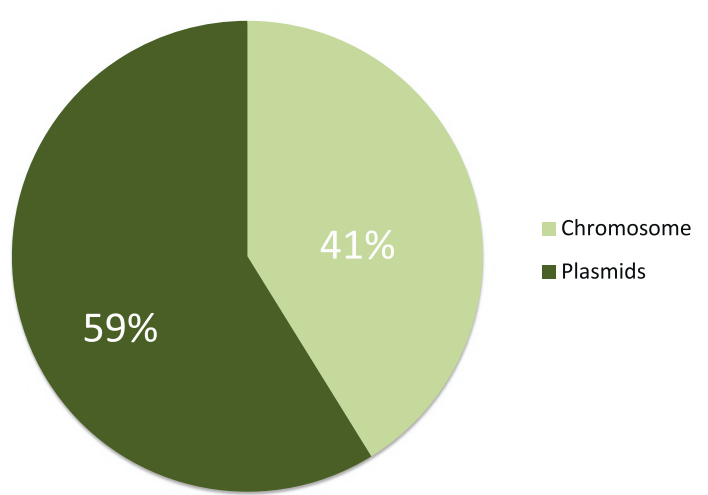

across the different replicons, we analysed the location of these genes. We found that $59 \%$ of the genes overexpressed under heat shock conditions were located on plasmids, whereas $41 \%$ were located on the chromosome. In contrast, under saline shock conditions, $69 \%$ of the over-expressed genes were located on the chromosome, and $31 \%$ were found on plasmids. In the case of the down-regulated genes, $90 \%$ and $80 \%$ were chromosomally encoded under heat and saline shock conditions, respectively (Figure 2). Additionally, although we found that the over-expressed genes in the heat shock sample were principally located on all plasmids, this trend was more exacerbated in pRet42c, pRet42d, pRet42e and pRet42f, and the over-expressed genes in the saline shock sample were located on the chromosome and pRet42a. These observations suggest that replicon contribution is different under each stress response, where the pRet42c, pRet42d, pRet42e and pRet42f plasmids could be preferentially involved during the heat shock response, and the chromosome and

\section{B)}
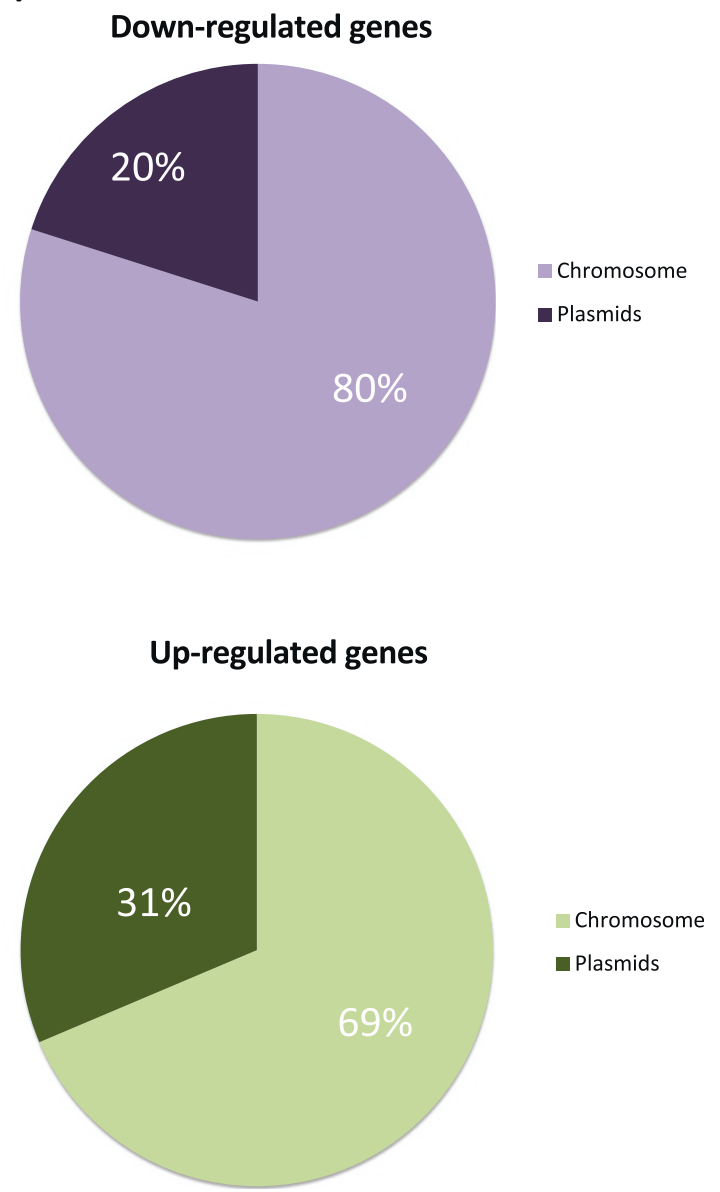

Figure $\mathbf{2}$ Chromosomal and plasmid genes are differentially expressed following heat and saline shock. Percentage of chromosomal and plasmid differentially expressed genes under $\mathbf{A}$ ) heat shock and $\mathbf{B}$ ) saline shock conditions. 
pRet42a plasmid could play more significant roles during the saline shock response (Figure 3).

\section{Functions involved in the stress responses}

To evaluate which functions are intrinsic to the stress responses, the differentially expressed genes were grouped using the COG and KEGG databases. We successfully grouped $87 \%$ of the genes that were differentially expressed under heat shock, $80 \%$ of the genes under saline shock and $85 \%$ of the genes that were differentially expressed under both conditions; the rest of the genes could not be assigned to either the COG or the KEGG database. As expected, many of the differentially expressed genes were grouped into functional categories and pathways that are known to participate in adaptations to heat stress, saline stress and other stressful conditions (Figure 4). We next identified the specific genes that are up- or down-regulated under each condition separately and under both conditions.

\section{Chaperones act exclusively in the heat shock response}

During the heat shock response, chaperones and proteases are involved in protein folding and the degradation of unfolded proteins, respectively [27-29]. Here, we found that dnaK, grpE, groESch, groEL, ibpA and $c l p B$ were up-regulated in $R$. etli during heat shock stress. Of them, dnaK and the members of the chromosomally located groESch2-groEL operon showed the highest transcriptional levels. These observations were confirmed by qRT-PCR (Additional file 2). Other heat shock genes were over-expressed in our RNA-Seq data, including groESf and groEL from plasmid pRet42f and two members (CHO1244 and CHO1245) of the HSP2O family of molecular chaperones. In total, fourteen heat shock proteins were over-expressed under heat shock conditions, whereas only two serine proteases $\left(\operatorname{degP} P h_{1}\right.$ and $\left.\operatorname{degPch} \mathrm{h}_{2}\right)$ were significantly over-expressed under saline shock conditions. Interestingly, no chaperones were found in the set of genes that was up-regulated under both conditions and numerous chaperones and proteases were down-regulated following saline shock (Additional file 3 ). These results could indicate that the recruitment of chaperone proteins seems to be exclusive to the heat shock response.

\section{Secondary metabolism is highly represented in the saline shock response}

We found that $g l p D, g l g X e$ and PEOOOOB were overexpressed under saline shock conditions. The genes $g \lg X$ and PE00008, which encode a glycosyl hydrolase (glycogen debranching) protein and a putative maltooligosyl trehalose synthase, respectively, may mediate glycogen accumulation during saline shock. According to the KEGG database, these genes are part of the tre $Y Z$ pathway (Additional file 3), which is involved in converting maltodextrins (e.g., glycogen) into trehalose. Our results suggest that $R$. etli uses the treYZ pathway for the de novo synthesis of compatible solutes (i.e., carbohydrates and disaccharides, such as sucrose and trehalose) under saline stress conditions [30]. We also found that $n d v A$, which is required for cyclic glucan biosynthesis [31], was down-regulated following saline shock and upregulated following heat shock. This is consistent with other studies that have shown a decrease in the expression levels of $n d v A$ and $n d v B$ when osmolarity increases in Agrobacterium tumefaciens [31,32].

\section{Over-expression of secretion and transporter systems is a} common response to heat and saline shock

Most bacterial genomes encode different secretion systems (such as toxin-antitoxin systems, pump efflux systems and $\mathrm{ABC}$ protein exporters), which provide versatile responses and adaptations to environmental changes. In our data, one heat shock-induced gene (CH00527) and three saline shock-induced genes (CH1305, CHO2813 and PFO0285) were found to be members of the HlyD family, which is a type I secretion system. Furthermore, we also found that components of the type IV secretion system were up-regulated during both the heat and saline shock responses; these genes included virB2a, PD00153 (virB 11 ), trbE (under heat shock), $v_{i r D_{2}}$, trbJ, trbD, trbB and PD00150 (VirB 8 ); notably, under saline shock, the up-regulation of trbI, trbG and $\operatorname{trbF}$ was also triggered (Additional file 3). Under heat and saline shock conditions, the largest functional category of up-regulated genes corresponded to carbohydrate transport and metabolism (COG G). Of these up-regulated genes, $71 \%$ were $\mathrm{ABC}$ transporters. We also found that $R$. etli over-expressed an ABC-type transporter for spermidine (CH03663) under saline shock conditions; spermidine and spermine are polyamine derivatives relevant to various cellular events, such as cell differentiation and membrane functions $[33,34]$. Therefore, we think that the large proportion of over-expressed $A B C$ transporters suggests that these transporters could be playing an important role in bacterial cell viability by exporting secondary metabolites (polyamines), disaccharides and amino acids to contend with the stressful conditions.

\section{Versatile responses of transcription factors}

Another functional category that was highly represented in $R$. etli during either the heat or saline stress responses was transcription (COG K). Twenty-six genes encoding transcriptional factors from the IclR, TetR, GntR and MarR families were up-regulated under heat shock conditions, while CHOO561, CHOO796, CHO3672 and $\mathrm{CHO4029,}$ which encode transcriptional factors of the 

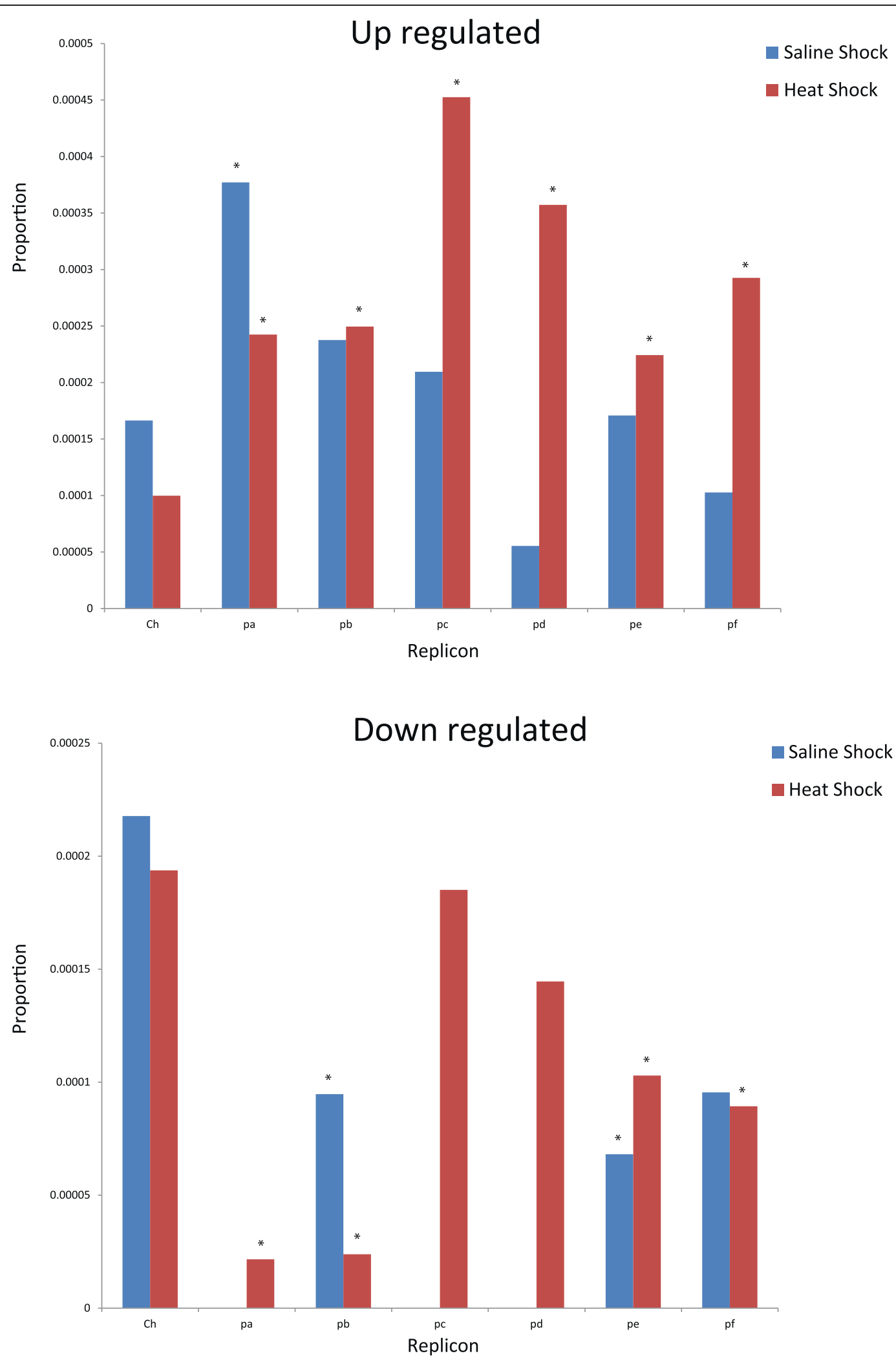

Figure 3 (See legend on next page.) 
(See figure on previous page.)

Figure 3 Replicon distribution of over-expressed genes following heat and saline shock. Proportions of the up-regulated gene contributions for each replicon. Axis labels correspond to: chromosome (Ch), plasmid pRet42a (pa), plasmid pRet42b (pb), plasmid pRet42c (pc), plasmid pRet42d (pd), plasmid pRet42e (pe), and plasmid pRet42f (pf). The proportions were obtained by normalising the number of up-regulated genes to the number of annotated genes for each replicon. * Indicates significant difference in the proportions of the up-regulated and down-regulated genes between the chromosome and plasmids (Two-sample for equality proportions with 99 percent confidence intervals).

MarR, LysR and TetR families, were over-expressed under saline shock conditions. It is known that bacteria express different sigma factors under different environmental conditions. Of the 23 sigma factors present in $R$. etli, we observed over-expression of three of them following saline shock: $C H 01118$ (ECF subfamily), rpoE $E_{4}$ $\left(\sigma^{28}\right)$ and $\mathrm{rpoH}_{2}\left(\sigma^{32}\right)$. The transcriptional factors identified here have been implicated in several processes [35-37], such as the osmotic shock and heat shock responses, among others (see Discussion), whereas one of the sigma factors, $r p o E_{4}$, has also been implicated in the saline and osmotic stress responses [36].

\section{Promoter regions and ncRNAs}

Thus far, we have considered the differentially expressed genes, but another important elements for the regulation of transcription are the promoter region and ncRNAs. First, to study the promoter regions in all of the noncoding regions associated with the genes over-expressed in both conditions, an in silico analysis to detect promoter motifs was conducted. Analysis of 266 upregulated transcriptional units identified a ggAAC- $\mathrm{N}_{16^{-}}$ cgTT sequence and a cTTGAc- $\mathrm{N}_{16}$-cnATAA sequence in 147 transcriptional units (approximately 16 to $50 \mathrm{nt}$ upstream relative to the ATG start codon), and this

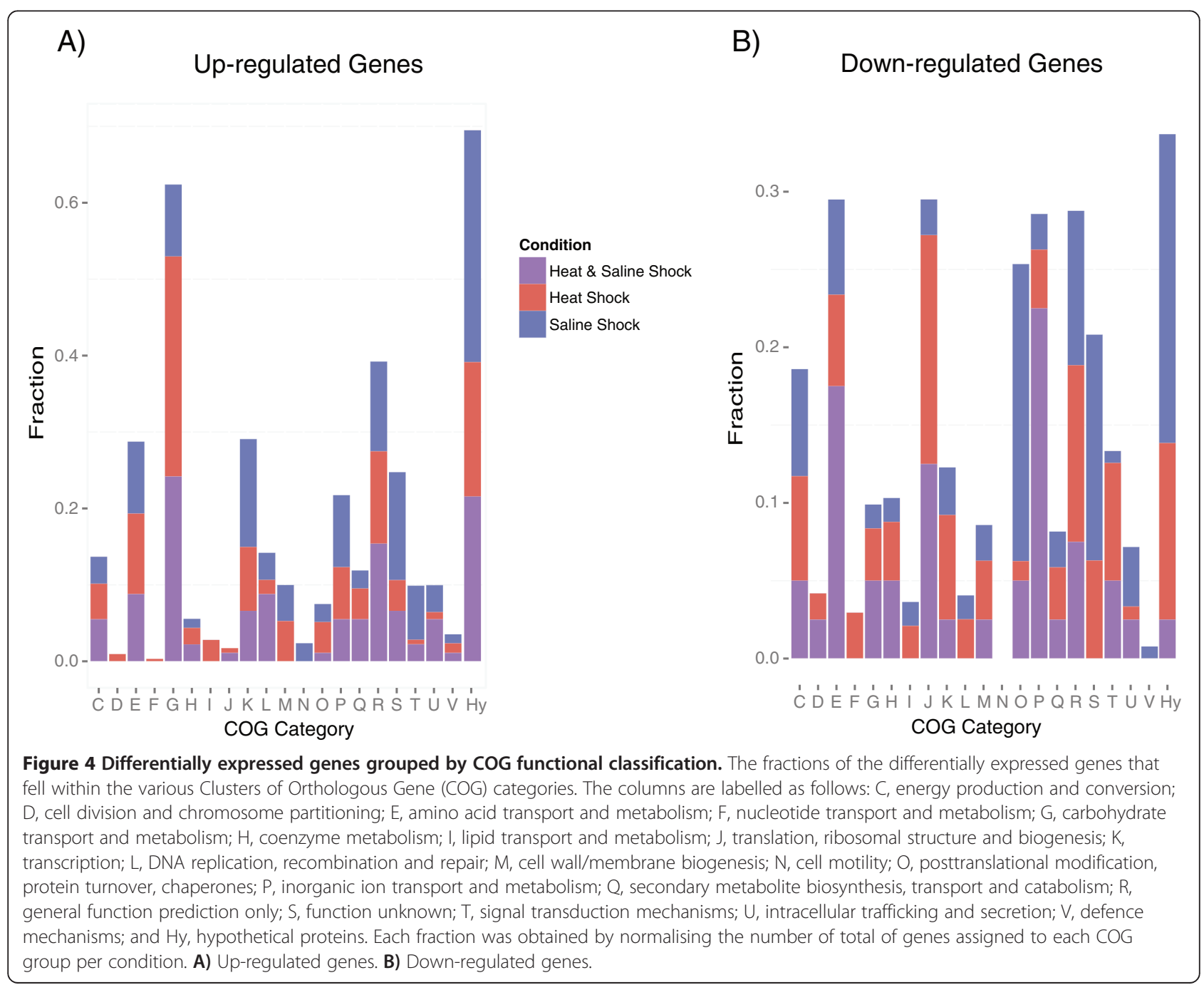


sequence perfectly matched the promoter consensus previously reported in $R$. etli for $\sigma^{28}\left(\mathrm{RpoE}_{4}\right.$ and PF00052-ECF) and $\sigma^{70}$ (SigA) [36,38,39]. An additional 105 motifs showed a cTTGaa- $\mathrm{N}_{16}$-CgATaT sequence, which is extremely similar to the S. meliloti's $\sigma^{32}\left(\mathrm{RpoH}_{1}\right.$ and $\mathrm{RpoH}_{2}$ ) reported motifs [40] (Figure 5). In our predictions, twenty-six putative promoters overlapped between $\mathrm{RpoH}$ and SigA, seven overlapped between $\mathrm{RpoH}$ and RpoE, six between RpoE and SigA and one among all three of these sigma factors (Additional file 4). Taken together, these results suggest that overlapping sigma promoter sequences could occur with high frequency and may be common in $R$. etli.

It is known that non-coding RNAs (ncRNAs) play an important role in bacterial gene expression; recent studies have identified ncRNAs in $R$. etli, and most of them are encoded in the intergenic regions [18]. Hence, to better understand the stress responses, we also conducted a screen to identify possible ncRNAs that are involved in these stress responses. We identified 107 intergenic regions of the $R$. etli genome that showed detectable and reproducible transcriptional activity (see Methods). Of the 107 regions, 89 had been previously reported as ncRNA candidates [18]. Eighteen regions (Table 1) revealed five (ReC106, ReC114, ReC115, ReC116 and ReC117) non-annotated proteins annotated in other genomes. Additionally, ReC103, ReC110, ReC112 and ReC113 matched hypothetical annotated proteins (YP_0025475 08.1, YP_001978587.1, WP_007533890.1 and WP_0100 07492.1, respectively) (Additional file 5). Among the remaining transcriptional units, $\mathrm{ReC} 108$ showed high levels of transcription, while $\mathrm{ReC101}, \mathrm{ReC} 102, \mathrm{ReC104}$, ReC105, ReC107, ReC118 and ReC111 showed low levels of transcription; these regions did not match any annotated proteins. Notably, $\mathrm{ReC} 101$ and $\mathrm{ReC} 102$ were located in the possible 5'-UTRs of their proximal genes, suggesting that they might be riboswitches. However, using Riboswitch finder and RiboSW (see Methods), these regions did not match any homologous riboswitches in other bacterial genomes; therefore, we considered them to be putative ncRNAs. We identified 13 differentially expressed ncRNAs under heat shock conditions and nine under saline shock conditions. Eight of the 13 differentially expressed ncRNAs were up-regulated following heat shock (ReCO6, ReC15, ReC20, ReC33, ReC55, ReC76, ReA01 and ReE02) and had been previously reported, including a well-characterised RNase P (ReC55). Under saline shock conditions, only two ncRNAs were over-expressed ( $\mathrm{ReC107}$ and $\mathrm{ReC64})$; of them, one was a novel ncRNA identified in this study (ReC107; Additional file 6). Next, we used matrix predictions (see Methods) to identify potential promoter elements in the regions 80-nt upstream of the over-expressed ncRNAs. Most of the ncRNA upstream regions harboured motifs for more than

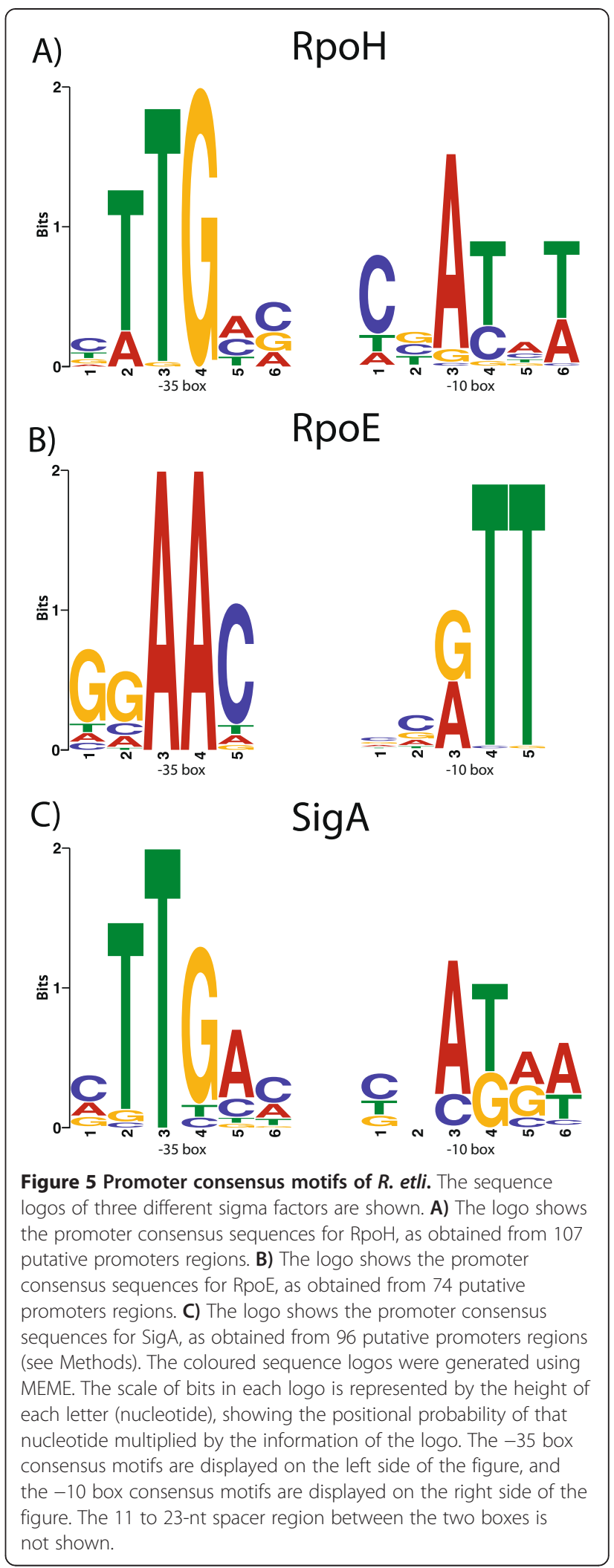


Table 1 Novel ncRNAs detected by RNA-Seq plotted data

\begin{tabular}{cccccc}
\hline Id & Start & Stop & Strand & Length & Prediction \\
\hline $\operatorname{ReC} 101$ & 672255 & 672116 & Minus & $140 \mathrm{bp}$ & ncRNA \\
$\operatorname{ReC} 102$ & 1331946 & 1331792 & Minus & $155 \mathrm{bp}$ & ncRNA \\
$\operatorname{ReC} 103$ & 1674693 & 1674827 & Plus & $135 \mathrm{bp}$ & Protein \\
$\operatorname{ReC} 104$ & 1747454 & 1747598 & Plus & $145 \mathrm{bp}$ & ncRNA \\
$\operatorname{ReC} 105$ & 1748816 & 1748663 & Minus & $154 \mathrm{bp}$ & ncRNA \\
$\operatorname{ReC} 106$ & 1749213 & 1748896 & Minus & $318 \mathrm{bp}$ & Protein \\
$\operatorname{ReC} 107$ & 1832463 & 1832580 & Plus & $118 \mathrm{bp}$ & ncRNA \\
$\operatorname{ReC} 108$ & 1839511 & 1839637 & Plus & $127 \mathrm{bp}$ & ncRNA \\
$\operatorname{ReC} 109$ & 1932797 & 1932959 & Plus & $163 \mathrm{bp}$ & ncRNA \\
$\operatorname{ReC} 110$ & 2475589 & 2475733 & Plus & $145 \mathrm{bp}$ & Protein \\
$\operatorname{ReC} 111$ & 2546193 & 2546004 & Minus & $190 \mathrm{bp}$ & ncRNA \\
$\operatorname{ReC} 112$ & 2763999 & 2764196 & Plus & $198 \mathrm{bp}$ & ncRNA \\
$\operatorname{ReC} 113$ & 2940023 & 2939896 & Minus & $128 \mathrm{bp}$ & ncRNA \\
$\operatorname{ReC} 114$ & 3416634 & 3416858 & Plus & $225 \mathrm{bp}$ & Protein \\
$\operatorname{ReC} 115$ & 3620823 & 3620581 & Minus & $243 \mathrm{bp}$ & Protein \\
$\operatorname{ReC} 116$ & 3634855 & 3634540 & Minus & $316 \mathrm{bp}$ & Protein \\
$\operatorname{ReC} 117$ & 3719937 & 3719559 & Minus & $379 \mathrm{bp}$ & Protein \\
$\operatorname{ReC} 118$ & 3776471 & 3776654 & Plus & $184 \mathrm{bp}$ & ncRNA \\
\hline
\end{tabular}

Table 1. Novel ncRNAs detected using the RNA-Seq plotted data. Eighteen transcribed regions were identified as novel ncRNAs or non-annotated proteins using Artemis (Graph, Add User Plot). The coordinates, strands and lengths of the ncRNAs and non-annotated proteins are shown (see the Methods section for more details).

one sigma factor, except for the novel ncRNA, ReC107, which yielded only a single putative SigA-dependent promoter. Rec06, Rec33 and Rec55 (RNase P) had putative RpoE-like and RpoH-like promoters while ReA01 and ReC64 harboured overlapping promoters for SigA and $\mathrm{RpoH}$. The fact that we were able to identify potential motifs for sigma factors in the upstream regions of the ncRNAs provides additional evidence to support the notion that these ncRNAs are real. However, in order to learn about the possible function of these ncRNAs futher research is required; we started working in that direction (Gamaliel López-Leal et al., in preparation). This analysis clearly indicates that ncRNAs are also playing a role in both the heat and saline shock stress responses.

\section{Discussion}

The main goal of this study was not only to identify genes that are differentially expressed during the saline and heat shock responses but also to characterise other regulatory elements, namely ncRNAs and sigma promoter motifs. In doing so, we think a more comprehensive view of bacterial gene regulation and new insights into the global response of $R$. etli under both stressful conditions can be obtained.

In this study, we considered two stressful conditions, saline and heat shock. We found that these two responses in such conditions are clearly different from each other. First, it seems that transcriptional regulation of the heat shock response involves many more genes. Second, the replicon contribution is different during each stress response; pRet42c, pRet42d, pRet42e and pRet42f plasmids are preferentially involved in the heat shock response, whereas the chromosome and pRet42a plasmid participate in the saline shock response (Figure 3). Previous studies have also suggested the importance of plasmids for stress responses [41-43]. For instance, roles of plasmids (pRet42d and $\mathrm{pRet} 42 \mathrm{~b}$ ) in nodule formation in $R$. etli and related species have been demonstrated [42]. Moreover, the contributions of pRet42a to pSym transfer and pRet42a, pRet $42 \mathrm{~b}$ and pRet $42 \mathrm{c}$ to heat shock tolerance have been shown $[43,44]$. Recent studies have shown that several bacteria have a clear genomic and transcriptional organisation $[41,45,46]$. For example, it was demonstrated Caulobacter crescentus has a chromosome that is spatially organised throughout its lifetime, and it was recently demonstrated that the naturally abundant groESL mRNA displayed a limited dispersion from its site of transcription during growth under normal and heat shock conditions. This result implies that the cell interior is functionally compartmentalised into small subcellular regions defined by the genetic map and organisation of the C. crescentus genome [45]. In $R$. etli, the chromosome and all of the plasmids encode active partition systems, which provide a specific location in the cell [47]. Taking this fact into account and considering the abundance of plasmid upregulated genes following heat and saline shock, it is reasonable to suppose that plasmids are important mobile elements that provide a transcriptional spatial compartment to help organise the response to stress. Moreover, the abundance of up-regulated genes related with the stress response in $R$. etli plasmids could be an important adaptive advantage because sets of genes required for particular environmental stresses can be horizontally acquired and distributed across $R$. etli populations in a fast and efficient way.

Another clear feature that differentiates these two responses is the specific functions that are involved in each response. Next, we discuss the functions activated under each response and those activated in response to both stresses. Chaperones and proteases are involved in protein folding and the degradation of unfolded proteins during the heat shock response [27-29]. Along these lines, we found that dnaK, grpE, $\operatorname{groESch}_{2}$, groEL, ibpA and $\operatorname{clpB}$ were up-regulated under heat shock stress. Furthermore, three of the proteins encoded by these genes (DnaK, GrpE, GroESL) help to maintain the correct folding of nascent polypeptides under non-stressful conditions but become essential for survival under heat shock conditions. For instance, in E. coli, the association of DnaK, DnaJ and $\mathrm{GrpE}$ is crucial for the regulation of the levels of $\mathrm{RpoH}$ $\left(\sigma^{32}\right)$ [48-50], which is involved in controlling the gene 
expression of heat shock proteins. Notably, both rpoH mutants in E. coli $[51,52]$ and $r p o H_{1}$ mutants in $R$. etli [37] are extremely sensitive to heat shock. Additionally, these heat shock proteins (dnaK, groEL, groES and grpE) have been also found over-expressed in Rhizobium tropici, which is recognized for its tolerance to high temperatures [53,54]. Remarkably, while 14 heat shock proteins were over-expressed following heat shock, only two serine proteases $\operatorname{degP} c h_{1}$ and $\operatorname{degPch}_{2}$ were significantly over-expressed under saline shock. These proteases were found to be involved in the elimination of inactive protein aggregates that accumulated in response to saline stress in S. meliloti [55-57]. Of note, the set of up-regulated genes shared in the two conditions did not include any chaperones; furthermore, numerous chaperones and proteases were down-regulated under saline shock condition (Additional file 3). Therefore, these results suggest that the recruitment of chaperone proteins seems to be exclusive to the heat shock response.

In Rhizobia, glycogen accumulation helps restore cell volume after osmotic shock [29], and high expression levels of $g \lg A 2, g \lg B 2$ and $g \lg X$ in $S$. meliloti support this conclusion [30]. A study in Rhizobium tropici PRF81 has reported that $\operatorname{glg} X$ together with nod-genes could be involved in the signal exchanges between host plant and rhizobia [58]. Here, we noted that $g l p D, g l g X e$ and PE00008 were over-expressed in $R$. etli under saline shock. These genes are part of the tre $Y Z$ pathway, which converts maltodextrins (e.g., glycogen) into trehalose, thus suggesting that $R$. etli uses the tre $Y Z$ pathway for the de novo synthesis of compatible solutes (i.e., carbohydrates and disaccharides, such as sucrose and trehalose) under saline stress conditions [30]. We think this might be true as trehalose and glycine betaine are known to function as osmotic stabilisers [59], and trehalose biosynthesis is a common response to osmotic stress in many bacteria [30,60]. All this information suggests that these genes have an important roll not only in the freeliving state during stressful conditions, but also in the symbiotic state with the host-plant $P$. vulgaris. Furthermore, in Rhizobium, the accumulation of betaine and trehalose allows the bacterium to survive under osmotic stress conditions and reduces the negative effects of $\mathrm{NaCl}[61]$.

Our data suggest that the over-expression of secretion and transporter systems may be a common response to both heat and saline shock responses. For instance, CH00527 and CH1305, CH02813, PF00285 were found to be members of a type I secretion system (HlyD family), which exports a variety of compounds, from drug molecules to large polypeptides, and is mainly involved in the secretion of noxious molecules across the cellular envelope [62-64]. Recent studies have suggested that type I secretion systems are involved in the translocation of unfolded proteins [65-68]. Additionally, a set of genes (virB2a, PD00153 [virB 11$], \operatorname{vir} D_{2}, \operatorname{trbJ}, \operatorname{trbD}, \operatorname{trbB}$ and $\left.P D 00150\left[\mathrm{VirB}_{8}\right]\right)$ from the type IV secretion system was up-regulated during both the heat and saline shock responses. Of note, under saline shock conditions, the upregulation of trbI, trbG and $t r b F$ is also triggered, whereas trbE is over-expressed following heat shock. Proteins from the type IV secretion system participate in a system that mediates the conjugative transfer of DNA with the extracellular milieu, and some even deliver DNA to fungi, plants or human cells $[63,64]$. Obviously, this process plays an important role in bacterial fitness under changing environmental conditions. Noticeably, under heat and saline shock conditions, the largest functional category of up-regulated genes corresponded to carbohydrate transport and metabolism (COG G) - most of these genes encode $\mathrm{ABC}$ transporters. These proteins belong to one of the two mayor groups of transporters indentified in gram-negative bacteria, which can carry a wide variety of substrates, including sugars, amino acids, polysaccharides and peptides [69-71]. This trend does not seem to be exclusive to $R$. etli, as the genomes of $\alpha$ proteobacteria tend to encode disproportionately large numbers of $\mathrm{ABC}$ transporters, reflecting their ecological versatility and their need to adapt to various conditions [8]. Following heat and saline shock, one-third of the up-regulated genes encode $\mathrm{ABC}$ transporters; of these genes, $18.5 \%$ were annotated as sugar transporters. In $S$. meliloti and other rhizobia, disaccharides have also been recognised as osmoprotectants [72]. We also found that ABC-type transporter for spermidine ( $\mathrm{CHO3663)}$ that was over-expressed following saline shock. Polyamines have been shown to be crucial for salt tolerance and the osmotic stress responses of soil microorganisms [73], as they can act as osmoprotectants because their cationic nature allows them to bind to proteins and lipids and thus stabilise cellular structures [74]. Additionally, we noted repression of the CH03629 gene under both conditions, which encodes an ornithine decarboxylase responsible for decarboxylating ornithine to putrescine, suggesting that at $30 \mathrm{~min}$ after induced stress, the synthesis of spermidine could be repressed. Therefore, we think that many of the over-expressed ABC transporters play an important role in cell viability by exporting secondary metabolites (polyamines), disaccharides and amino acids to contend with the stressful conditions. Besides, these ABC transporters could be part of the general stress response in $R$. etli.

Sigma factors are key to the stress response, as the use of alternative sigma factors creates flexibility in bacterial adaptation. Here, we observed over-expression of three sigma factors following saline shock: $\mathrm{CH} 01118$ (ECF subfamily), $r p o E_{4}\left(\sigma^{28}\right)$ and $r p o H_{2}\left(\sigma^{32}\right)$. In $R$. etli, $\mathrm{RpoE}_{4}$ 
participates under oxidative, saline and osmotic stresses and also controls the expression of $\mathrm{rpoH}_{2}$, whereas $\mathrm{rpoH}_{2}$ mutants were reported to be sensitive to $\mathrm{NaCl}$ shock $[36,37]$. Thus, these two genes play roles in cell survival during the saline shock response. We also detected constitutive expression of $\mathrm{rpoH}_{1}$ under heat shock and in the reference condition, which was previously shown to be essential for the heat shock response in $R$. etli [37]. Similar patterns have been observed in other bacteria, where the levels of mRNA-rpoH are maintained at a basal concentration [75]. In $E$. coli, the mRNA of rpoH contains a thermo-switch within the 5'-UTR of the mRNA [76] that under non-stressful conditions blocks the translation of the rpoH gene, whereas under stressful conditions (e.g., heat shock) allows the translation of $r p o H$ [76]. Studies in B. japonicum have demonstrated that this level of regulation is also present in rhizobial species [77]. For example, some heat shock genes are translationally controlled by a secondary mRNA structure called ROSE (repression of heat shock gene expression); this regulatory element mainly affects genes that encode small heat shock proteins, but it also controls $r p o H_{1}$, which encodes one of the three $\sigma^{32}$ factors in B. japonicum [77]. Future studies are warranted to investigate whether an analogous mechanism exists in $R$. etli. Additionally, the regulatory region of $r p o H_{1}$ in $\mathrm{R}$. etli contains two promoters: one for $\sigma^{70}$ and one for $\sigma^{28}$ [37]. These results indicate that the constitutive expression of $r p o H_{1}$ in $R$. etli could be regulated by its primary sigma factor $\left(\sigma^{70}\right)$. However, the qRT-PCR expression data revealed that $\mathrm{CHO1118}$ is differentially expressed under heat shock, in contrast with the observed data in the RNA-Seq analyses. These results could be explained by the fact that in the qRT-PCR experiments, the cDNAs were obtained with specific primers, ensuring that the cDNA belonged to the target gene. Additionally or alternatively, the biological noise in our RNA-Seq libraries could be the reason for this (see Methods). Nonetheless, the regulation of $\mathrm{RpoH}$ by $\mathrm{RpoE}$ is retained in many bacteria. In this study, we identified the over-expression of three sigma factors; two of them belong to sigma factor RpoE family, which could regulate the $\mathrm{RpoH}$ sigma factors in $R$. etli under heat and saline shock. However, further studies on the 18 ECF-sigma factors and their targets should be performed in $R$. etli because the regulatory networks of these sigma factors have not been fully explored.

The identified promoter motifs were expected as the transcriptomes were obtained under stressful conditions, where both $\mathrm{RpoH}_{1}$ and $\mathrm{RpoH}_{2}$ are essential. Clearly, this approach does not discriminate promoter motifs between the alternative sigma factors $\mathrm{RpoH}_{1}-\mathrm{RpoH}_{2}$ and $\mathrm{RpoE}_{4}-\mathrm{CH01118-ECF.} \mathrm{However,} \mathrm{studies} \mathrm{of} \mathrm{the} R$. etli regulons $\mathrm{RpoE}_{4}$ and PF00052-ECF have identified a unique sequence motif, which has been recognised for both ECF-type sigma factors, resulting in a large number of overlapping regulated genes [35]. Moreover, analysis of RpoH's regulons in $S$. meliloti has identified the same tendency of a high number of similar sequences in their promoters [40]. A recently massive exploration and mapping of $\sigma^{\mathrm{H}}, \sigma^{\mathrm{E}}$ and $\sigma^{70}$ promoters in S. meliloti revealed highly similar promoter sequences between alternative sigma factor copies [78]. These results indicated that the regulation of the different sigma factors in a given genome could depend on alternative and more complex regulatory systems that include the participation of transcriptional factors, riboswitches, ncRNAs and posttranslational regulatory strategies. Therefore, specific sequence-promoter recognition may be limited to a few events. In support of this idea, it is well known that in $E$. coli and other bacterial genomes, promoters belonging to the $\sigma^{70}$ family can overlap $[35,52,79,80]$. For instance, in the case of E. coli, overlapping RpoH and RpoD $\left(\sigma^{70}\right)$ promoters have also been reported [81]. Here, we note that in the overlapped promoters, the -35 box was maintained in the two promoter predictions, and only the -10 box was displaced. In most cases, this displacement involved only a few bases in either direction (upstream or downstream). This result is also supported by the observation of lax promoter recognition in $R$. etli (principally in the -10 box) [39] and by the occurrence of additional promoter-like signals that could play a regulatory role. In bacteria, the promoter-like signals tend to be generated easily, resulting in selection for functionally redundant promoter sequences [82]. Alternatively, the complex regulation of the -10 box has led several authors to consider that it may comprise a different type of promoter [2]. In E. coli, the -10 box (unlike the -35 box) is not a single recognition element; instead, it seems to function as two recognition elements: one primarily positioned at -12 in the double strand and another based on the melting of the -11 to -7 positions in a single strand [2]. Our results, along with the findings from other studies, suggest that the overlapping of motifs for the different sigma factors might be a common occurrence, which in turn suggests that additional elements (riboswitches, ncRNAs and post-transcriptional regulatory elements) could be playing roles in determining the specificity of any given stress response.

The regulatory networks that allow bacteria to respond to different environmental stresses usually comprise transcriptional regulators, sigma factors, proteases and small ncRNAs [18]. In this work, we identified 13 differentially expressed ncRNAs under heat shock and 9 under saline shock conditions. Of note, this result is consistent with our finding that more genes are upregulated during the heat shock stress response, as here we also find that more ncRNAs were up-regulated during that stress response. We think these ncRNAs are real entities for several reasons. First, some of them have 
been previously reported. In the case of the heat shock response, eight of the up-regulated ncRNAs (ReCO6, ReC15, ReC20, ReC33, ReC55, ReC76, ReA01 and ReE02) were previously described $[18,83]$, whereas under saline shock conditions, two ncRNAs ( $\mathrm{ReC} 107$ and ReC64) were identified previously [18]. Secondly, we detected reproducible transcriptional activity (in biological replicates); besides, sigma promoter motifs were identified for some of these ncRNAs. The analysis on ncRNAs in this work show that these molecules are an important part of the response to both heat and saline shock stress, future studies are required to establish relevance of these molecules in such stresses.

In considering the results, we believe that the heat shock response is more complex than the saline shock response. Not only does the heat shock response involve more differentially expressed genes and more ncRNAs, it also uses more replicons. Further studies are required to establish if these observations also occur at the translational level.

\section{Conclusions}

We think our work exemplifies how the utilisation of approaches that consider more than just the differentially expressed genes and also include regulatory elements of the stress response provide a more comprehensive view of bacterial gene regulation. More specifically, this study gives new insights into the global response of $R$. etli under both stressful conditions.

\section{Methods}

\section{Culture conditions}

Nine independent cultures of wild-type Rhizobium etli CE3 [84] were grown at $30^{\circ} \mathrm{C}$ with agitation (200 rpm) in peptone-yeast extract (PY) medium [85]. When required, nalidixic acid $\left(20 \mu \mathrm{g} \mathrm{ml}^{-1}\right)$ was added to the cultures. Aliquots $(10 \mathrm{ml})$ were taken from all of the cultures at 12 hours post-inoculation $\left(\mathrm{OD}_{600} \approx 0.4\right.$, exponential phase) and incubated for $30 \mathrm{~min}$ at $30^{\circ} \mathrm{C}$ in PY medium (reference condition), at $42^{\circ} \mathrm{C}$ in PY medium (heat shock condition) or at $30^{\circ} \mathrm{C}$ in PY medium containing $80 \mathrm{mM} \mathrm{NaCl}$ (saline shock condition).

\section{RNA extraction and sequencing}

Each sample was centrifuged at 13,000 rpm for $10 \mathrm{~min}$, and the pellet was washed four times with $1 \mathrm{ml}$ of Tris: EDTA buffer $50 / 20$ (pH 8.0) and $500 \mu$ l of RNAlater solution (Ambion). Total RNA was isolated using an RNeasy Midi Kit (Qiagen) according to the manufacturer's instructions. We verified the amount and quality of the resulting total RNA samples by agarose gel electrophoresis, as previously reported [86].

Ribosomal RNA was eliminated using a RiboMinus Kit (Life Technologies), which was used according to a modified version of the manufacturer's recommended protocol. Briefly, a second rRNA elimination step using the Terminator Exonuclease enzyme (Epicenter), which uses RNA monophosphate as a substrate while leaving mRNA intact, was included in the protocol. RNA integrity was assessed using an Agilent Bioanalyzer 2100 and an RNA Nano 6000 Labchip Kit (Agilent Technologies). RNA sequencing was carried out by the Unidad Universitaria de Secuenciación Masiva de DNA (UUSMD)-UNAM (http:// www.uusmd.unam.mx/), using a Next Generation High Throughput Sequencing Genome Analyzer IIx (GAllx; Illumina).

\section{Quantitative reverse transcription PCR}

Quantitative reverse transcription PCR (qRT-PCR) of twenty-seven selected genes was performed. These selected genes represented differentially and non-differentially expressed genes under heat and saline shock conditions observed by RNA-Seq analysis. Total RNA was obtained from nine independent cultures (representing the nine RNA-Seq libraries) using an RNeasy Midi Kit (Qiagen). Total RNA (DNA free) was reverse transcribed into cDNA using the RevertAid $\mathrm{H}$ minus First Strand cDNA Synthesis kit (Thermo Scientific). Quantitative PCR was performed using a PCR system 3700 (Applied Biosystems). The expression levels of target genes were normalised to the expression level of the reference gene his $C d$. The fold changes of three biological and technical replicates for each condition were obtained using the $\Delta \Delta C_{t}$ method [87]. The detected genes and primers are listed in Additional file 7.

\section{Mapping and analysis of RNA-Seq data}

RNA-Seq data were aligned using Bowtie (http://bowtie-bio.sourceforge.net), with the R. etli CFN42 genome (ftp://ftp.ncbi.nlm.nih.gov/genomes/Bacteria/Rhizobium_etli_CFN_42_uid58377/) as the reference genome. Our mapping parameters were set to align the best quality reads (--phred64-quals), report the best alignment and allow zero mismatches. To adjust the values in the biological replicates, the RNA-Seq data were preprocessed. The raw count expression profiles were preprocessed by the total number of reads from the library for each condition. This type of adjustment has also been performed by other packages [88].

A Perl script was written to determine the expression value of each gene, which used the output files of Bowtie. To visualise our RNA-Seq expression data, we used the output files of MAQ aligner (http://maq.sourceforge.net/ maq-man.shtml); the quality parameter used in the MAQ pileup was $\mathrm{q} 30$, and zero mismatches were allowed. We built plots using the solexa2plots.pl script, which was generated based on the instructions in [89]. The output files could then be read into the Artemis software (http://www. sanger.ac.uk/resources/software/artemis/). 


\section{Identification of novel ncRNAs and ORFs}

To identify novel ncRNAs and non-annotated ORFs, we used the plots visualised in Artemis (see above) to manually identify the transcribed non-coding regions. The transcribed non-coding regions were then checked for folding using the RNA fold tool (http://rna.tbi.univie.ac.at/cgi-bin/ RNAfold.cgi) and assessed to identify which strand could be transcribed. Basic Local Alignment Search Tool (BLAST; http://blast.ncbi.nlm.nih.gov) searches were used to verify that the regions did not match with proteins annotated in other genomes. The parameters used to identify nonannotated proteins were as follows: > 90\% coverage of the subject protein and $>30 \%$ identity. We used this approach in conjunction with searches of the Rfam (http://rfam.sanger.ac.uk/) and miRBase (http://www. mirbase.org/) databases.

\section{Assessment of differentially expressed genes}

To reduce the noise between the RNA-Seq replicates caused by differences in sequencing depth, we preprocessed the raw-count data by dividing them with the total number of reads from the library. We obtained Pearson's correlation coefficients of $0.75,0.74$ and 0.75 for between-replicates for the reference, heat and saline shock conditions, respectively. These results are consistent with previous reports [18]. Because our biological replicates of the RNA-Seq data had different sequencing depths, we used the NOISeq package (http://bioinfo.cipf. es/noiseq/) to detect differential expression. We performed our analysis according to the provided instructions. We normalised our pre-processed data using the upper quartile method [18,88-92] and applied $\mathrm{k}=0.5$ as recommended for normalised data in the NOISeq manual.

\section{Functional categorisation of genes}

We used the Clusters of Orthologous Groups (COG; http://www.ncbi.nlm.nih.gov/COG/) and KEGG Automatic Annotation Server (KAAS; http://www.genome.jp/ tools/kaas/; http://www.genome.jp/kegg/) databases to cluster the differentially expressed genes into functional categories and assign them to metabolic pathways.

\section{Consensus motifs}

To identify promoter-like signals, we used the RSA tools (http://rsat.ulb.ac.be/). We built matrices for three sigma factors (RpoH, RpoE, and SigA) using the reported consensus sequences of SigA and RpoE in $R$. etli [36,39] and those of RpoH and SigA in S. meliloti $[38,40]$. We identified genes that were up-regulated in response to the two stress conditions and searched the 80 nucleotides (nt) upstream of their start codons for promoter-like signals. In cases where the transcriptional profiles appeared to start $>80$ nucleotides upstream from the start codon, we used our RNA-Seq data plots to identify the potential promoter. To search for the sigma-factor-binding motifs, we used the matrix-scan tool from RSA tools (http:// embnet.ccg.unam.mx/rsa-tools/). For our analysis of logo consensus sequences, we used the RSA tools consensus service and the Multiple Em for Motif Elicitation program (http://meme.nbcr.net). The identified promoters are listed in Additional file 8.

\section{RNA-Seq data accession number}

The RNA-Seq sequence data have been deposited in the GEO (Gene Expression Omnibus) database under the accession number GSE50018.

\section{Additional files}

Additional file 1: General features of the total sequenced and mapped reads. General features of the total sequenced and mapped reads. The reads were mapped using Bowtie aligner with zero mismatch criteria and the best quality reads (--phred64-quals). See the Methods section for more details.

Additional file 2: qRT-PCR fold changes of twenty-seven selected genes observed by RNA-Seq. Fold difference values were calculated using the $\Delta \Delta C_{t}$ method and normalised to the reference gene his $C d$ for 27 selected genes with differential and non-differential expression observed in the RNA-Seq data. Fold change values were obtained as an average over three biological and technical replicates.

Additional file 3: The Gen ID and COG designations of the genes that were up- and down-regulated in $R$. etli under heat and saline shock conditions.

Additional file 4: Sigma-factor overlap among the promoters of genes that were up-regulated under heat and saline shock conditions. Proportional Venn diagram of promoters with sigma-factor overlap for the genes that were up-regulated under heat and saline shock conditions. Independent of the tested conditions, 71, 62 and 60 promoters appeared to be exclusive to $\mathrm{RpoH}$, SigA and RpoE, respectively, while twenty-six promoters overlapped between $\mathrm{RpoH}$ and SigA, seven overlapped between $\mathrm{RpoH}$ and RpoE, six between SigA and RpoE, and one across all three sigma factors.

Additional file 5: BLAST analysis of ncRNAs and non-annotated proteins.

Additional file 6: Differential expression of novel ncRNAs.

Additional file 7: Gene and primer sequences for qRT-PCR analysis.

Additional file 8: Putative sigma factor dependent promoters.

Competing interests

The authors declare that they have no competing interests.

\section{Authors' contributions}

MARR conceived the initial study. GLL designed and performed the experiments. GLL and AMV performed the removal of rRNA from the samples. GLL and MLT performed the CDNA synthesis and qRT-PCR analysis. GLL analysed the data and wrote the manuscript. GD and MARR reviewed and edited the manuscript. SCR reviewed, edited and structured the manuscript. GD and MARR participated in general discussions and provided financial support. All of the authors read and approved the final manuscript.

\section{Authors' information}

This research was conducted by GLL in partial fulfilment of the requirements for a Ph.D. in Ciencias Biomédicas from the UNAM, Cuernavaca, México. 


\section{Acknowledgements}

We gratefully acknowledge David Romero, Susana Brom, Margareta Boege and Miguel Cevallos for their helpful comments on the manuscript, Luis Lozano for help with the bioinformatics analysis, Elide Carmona for editing the figures, Rosa Isela Santamaría and Orlando Santillán for their skilful technical support, Ricardo Grande (Unidad Universitaria de Secuenciación Masiva de DNA, UNAM) for help with the RNA-Seq library, and Cyntia Méndez for support regarding the RNA extraction. This work was supported by Consejo Nacional de Ciencia y Tecnología (CONACyT) grant 154833. GLL was supported during the Ph.D. program (Programa de Doctorado en Ciencias Biomédicas, Universidad Nacional Autónoma de México) by a scholarship from CONACyT.

\section{Author details}

'Programa de Genómica Evolutiva, Centro de Ciencias Genómicas, Universidad Nacional Autónoma de México, Apartado Postal 565-A, Cuernavaca, Morelos C.P 62210, México. ${ }^{2}$ Departamento de Microbiología Molecular, Instituto de Biotecnología, Universidad Nacional Autónoma de México, Cuernavaca, Morelos C.P 62120, México. Instituto Nacional de Medicina Genómica, Secretaría de Salud, Periférico Sur No. 4809, México, DF 14610, México. ${ }^{4}$ Oncomedic. Cuauhtémoc 84A, Col, Torrielo Guerra, México, DF C.P. 14050, México.

Received: 28 April 2014 Accepted: 3 September 2014

Published: 8 September 2014

\section{References}

1. Ghosh T, Bose D, Zhang X: Mechanisms for activating bacterial RNA polymerase. FEMS Microbiol Rev 2010, 34(5):611-627.

2. Hook-Barnard IG, Hinton DM: Transcription initiation by mix and match elements: flexibility for polymerase binding to bacterial promoters. Gene Regul Syst Bio 2007, 1:275-293.

3. Lloyd G, Landini P, Busby S: Activation and repression of transcription initiation in bacteria. Essays Biochem 2001, 37:17-31.

4. Kazmierczak MJ, Wiedmann M, Boor KJ: Alternative sigma factors and their roles in bacterial virulence. Microbiol Mol Biol Rev 2005, 69(4):527-543.

5. Browning DF, Busby SJ: The regulation of bacterial transcription initiation. Nat Rev Microbiol 2004, 2(1):57-65.

6. Molina N, van Nimwegen E: Universal patterns of purifying selection at noncoding positions in bacteria. Genome Res 2008, 18(1):148-160.

7. Cordero OX, Hogeweg P: Large changes in regulome size herald the main prokaryotic lineages. Trends Genet 2007, 23(10):488-493.

8. Konstantinidis KT, Tiedje JM: Trends between gene content and genome size in prokaryotic species with larger genomes. Proc Natl Acad Sci U S A 2004, 101(9):3160-3165.

9. Balleza E, Lopez-Bojorquez LN, Martinez-Antonio A, Resendis-Antonio O, Lozada-Chavez I, Balderas-Martinez YI, Encarnacion S, Collado-Vides J: Regulation by transcription factors in bacteria: beyond description. FEMS Microbiol Rev 2009, 33(1):133-151.

10. Paget MS, Helmann JD: The sigma70 family of sigma factors. Genome Biol 2003, 4(1):203.

11. Rodionov DA, Novichkov PS, Stavrovskaya ED, Rodionova IA, Li X, Kazanov MD, Ravcheev DA, Gerasimova AV, Kazakov AE, Kovaleva GY, Permina EA, Laikova ON, Overbeek R, Romine MF, Fredrickson JK, Arkin AP, Dubchak I, Osterman AL, Gelfand MS: Comparative genomic reconstruction of transcriptional networks controlling central metabolism in the Shewanella genus. BMC Genomics 2011, 12(Suppl 1):S3.

12. Gottesman S, Storz G: Bacterial small RNA regulators: versatile roles and rapidly evolving variations. Cold Spring Harb Perspect Biol 2011, 3(12):1-16.

13. Bouché F, Bouché JP: Genetic evidence that DicF, a second division inhibitor encoded by the Escherichia coli dicB operon, is probably RNA. Molecular Microbiology 1989, 3(7):991-994.

14. Kazantsev AV, Pace NR: Bacterial RNase P: a new view of an ancient enzyme. Nat Rev Micro 2006, 4(10):729-740.

15. Muto A, Ushida C, Himeno $\mathrm{H}$ : A bacterial RNA that functions as both a tRNA and an mRNA. Trends in Biochemical Sciences 1998, 23(1):25-29.

16. Frohlich KS, Vogel J: Activation of gene expression by small RNA. Curr Opin Microbiol 2009, 12(6):674-682.

17. Del Val C, Rivas E, Torres-Quesada O, Toro N, Jiménez-Zurdo Jl: Identification of differentially expressed small non-coding RNAs in the legume endosymbiont Sinorhizobium meliloti by comparative genomics. Mol Microbiol 2007, 66(5):1080-1091.
18. Vercruysse M, Fauvart $M$, Cloots $L$, Engelen $K$, Thijs IM, Marchal $K$, Michiels J: Genome-wide detection of predicted non-coding RNAs in Rhizobium etli expressed during free-living and host-associated growth using a highresolution tiling array. BMC Genomics 2010, 11:53.

19. Wilms I, Voss B, Hess WR, Leichert LI, Narberhaus F: Small RNA-mediated control of the Agrobacterium tumefaciens GABA binding protein. Mol Microbiol 2011, 80(2):492-506.

20. Gonzalez V, Santamaria RI, Bustos P, Hernandez-Gonzalez I, Medrano-Soto A, Moreno-Hagelsieb G, Janga SC, Ramirez MA, Jimenez-Jacinto V, ColladoVides J, Davila G: The partitioned Rhizobium etli genome: genetic and metabolic redundancy in seven interacting replicons. Proc Natl Acad Sci U S A 2006, 103(10):3834-3839.

21. Galibert F, Finan TM, Long SR, Puhler A, Abola P, Ampe F, Barloy-Hubler F, Barnett MJ, Becker A, Boistard P, Bothe G, Boutry M, Bowser L, Buhrmester J, Cadieu E, Capela D, Chain P, Cowie A, Davis RW, Dreano S, Federspiel NA, Fisher RF, Gloux S, Godrie T, Goffeau A, Golding B, Gouzy J, Gurjal M, Hernandez-Lucas I, Hong A, Huizar L, et al: The composite genome of the legume symbiont Sinorhizobium meliloti. Science 2001, 293(5530):668-672

22. Gourion B, Sulser S, Frunzke J, Francez-Charlot A, Stiefel P, Pessi G, Vorholt $J A$, Fischer HM: The PhyR-sigma(EcfG) signalling cascade is involved in stress response and symbiotic efficiency in Bradyrhizobium japonicum. Mol Microbiol 2009, 73(2):291-305.

23. Kaneko T, Nakamura Y, Sato S, Minamisawa K, Uchiumi T, Sasamoto S, Watanabe A, Idesawa K, Iriguchi M, Kawashima K, Kohara M, Matsumoto M, Shimpo S, Tsuruoka H, Wada T, Yamada M, Tabata S: Complete genomic sequence of nitrogen-fixing symbiotic bacterium Bradyrhizobium japonicum USDA110. DNA Res 2002, 9(6):189-197.

24. Mittenhuber $\mathrm{G}$ : An inventory of genes encoding RNA polymerase sigma factors in 31 completely sequenced eubacterial genomes. J Mol Microbiol Biotechnol 2002, 4(1):77-91.

25. Nogales J, Campos R, BenAbdelkhalek H, Olivares J, Lluch C, Sanjuan J: Rhizobium tropici genes involved in free-living salt tolerance are required for the establishment of efficient nitrogen-fixing symbiosis with Phaseolus vulgaris. Mol Plant Microbe Interact 2002, 15(3):225-232.

26. Zahran HH: Rhizobium-legume symbiosis and nitrogen fixation under severe conditions and in an arid climate. Microbiol Mol Biol Rev 1999, 63(4):968-989. table of contents.

27. Liberek K, Galitski TP, Zylizz M, Georgopoulos C: The DnaK chaperone modulates the heat shock response of Escherichia coli by binding to the sigma 32 transcription factor. Proc Natl Acad Sci U S A 1992, 89(8):3516-3520.

28. Nonaka G, Blankschien M, Herman C, Gross CA, Rhodius VA: Regulon and promoter analysis of the $E$. coli heat-shock factor, sigma32, reveals a multifaceted cellular response to heat stress. Genes Dev 2006, 20(13):1776-1789.

29. Thomas JG, Baneyx F: Roles of the Escherichia coli small heat shock proteins IbpA and IbpB in thermal stress management: comparison with ClpA, ClpB, and HtpG In vivo. J Bacteriol 1998, 180(19):5165-5172.

30. Vriezen JA, de Bruijn FJ, Nusslein K: Responses of rhizobia to desiccation in relation to osmotic stress, oxygen, and temperature. Appl Environ Microbiol 2007, 73(11):3451-3459.

31. Breedveld MW, Miller KJ: Cyclic beta-glucans of members of the family Rhizobiaceae. Microbiol Rev 1994, 58(2):145-161.

32. Roset MS, Ciocchini AE, Ugalde RA, Inon de lannino N: Molecular cloning and characterization of cgt, the Brucella abortus cyclic beta-1,2-glucan transporter gene, and its role in virulence. Infect Immun 2004, 72(4):2263-2271.

33. Schuber F: Influence of polyamines on membrane functions. Biochem J 1989, 260(1):1-10.

34. Tabor CW, Tabor H: Polyamines in microorganisms. Microbiol Rev 1985, 49(1):81-99.

35. Jans A, Vercruysse M, Gao S, Engelen K, Lambrichts I, Fauvart M, Michiels J: Canonical and non-canonical EcfG sigma factors control the general stress response in Rhizobium etli. Microbiologyopen 2013, 2(6):976-987.

36. Martinez-Salazar JM, Salazar E, Encarnacion S, Ramirez-Romero MA, Rivera J: Role of the extracytoplasmic function sigma factor RpoE4 in oxidative and osmotic stress responses in Rhizobium etli. J Bacteriol 2009, 191(13):4122-4132.

37. Martinez-Salazar JM, Sandoval-Calderon M, Guo X, Castillo-Ramirez S, Reyes A, Loza MG, Rivera J, Alvarado-Affantranger X, Sanchez F, Gonzalez V, Davila G Ramirez-Romero MA: The Rhizobium etli $\mathrm{RpoH} 1$ and $\mathrm{RpoH} 2$ sigma factors are involved in different stress responses. Microbiology 2009, 155(Pt 2):386-397. 
38. MacLellan SR, MacLean AM, Finan TM: Promoter prediction in the rhizobia. Microbiology 2006, 152(Pt 6):1751-1763.

39. Ramirez-Romero MA, Masulis I, Cevallos MA, Gonzalez V, Davila G: The Rhizobium etli sigma70 (SigA) factor recognizes a lax consensus promoter. Nucleic Acids Res 2006, 34(5):1470-1480.

40. Barnett MJ, Bittner AN, Toman CJ, Oke V, Long SR: Dual RpoH sigma factors and transcriptional plasticity in a symbiotic bacterium. J Bacteriol 2012, 194(18):4983-4994

41. Amster-Choder O: The compartmentalized vessel: The bacterial cell as a model for subcellular organization (a tale of two studies). Cell Logist 2011 1(2):77-81.

42. Brom S, Garcia de los Santos A, Stepkowsky T, Flores M, Davila G, Romero D, Palacios R: Different plasmids of Rhizobium leguminosarum bv. phaseoli are required for optimal symbiotic performance. J Bacteriol 1992, 174(16):5183-5189.

43. Brom S, Garcia-de los Santos A, Cervantes L, Palacios R, Romero D: In Rhizobium etli symbiotic plasmid transfer, nodulation competitivity and cellular growth require interaction among different replicons. Plasmid 2000, 44(1):34-43.

44. Mercado-Blanco J, Toro N: Plasmids in Rhizobia: The Role of Nonsymbiotic Plasmids. Mol Plant Microbe Interact 1996, 9(7):535-545.

45. Montero Llopis P, Jackson AF, Sliusarenko O, Surovtsev I, Heinritz J, Emonet $T$, Jacobs-Wagner C: Spatial organization of the flow of genetic information in bacteria. Nature 2010, 466(7302):77-81.

46. Toro E, Shapiro L: Bacterial chromosome organization and segregation. Cold Spring Harb Perspect Biol 2010, 2(2):a000349.

47. Kahng LS, Shapiro L: Polar localization of replicon origins in the multipartite genomes of Agrobacterium tumefaciens and Sinorhizobium meliloti. J Bacteriol 2003, 185(11):3384-3391.

48. Rodriguez F, Arsene-Ploetze F, Rist W, Rudiger S, Schneider-Mergener J, Mayer MP, Bukau B: Molecular basis for regulation of the heat shock transcription factor sigma32 by the DnaK and DnaJ chaperones. Mol Cell 2008, 32(3):347-358.

49. Rosen R, Ron EZ: Proteome analysis in the study of the bacterial heatshock response. Mass Spectrom Rev 2002, 21(4):244-265.

50. Zhao K, Liu M, Burgess RR: The global transcriptional response of Escherichia coli to induced sigma 32 protein involves sigma 32 regulon activation followed by inactivation and degradation of sigma 32 in vivo. J Biol Chem 2005, 280(18):17758-17768.

51. Calendar R, Erickson JW, Halling C, Nolte A: Deletion and insertion mutations in the rpoH gene of Escherichia coli that produce functional sigma 32. J Bacterio/ 1988, 170(8):3479-3484.

52. Dufour YS, Imam S, Koo BM, Green HA, Donohue TJ: Convergence of the transcriptional responses to heat shock and singlet oxygen stresses. PLOS Genet 2012, 8(9):e1002929.

53. Gomes DF, Batista JS, Schiavon AL, Andrade DS, Hungria M: Proteomic profiling of Rhizobium tropici PRF 81: identification of conserved and specific responses to heat stress. BMC Microbiol 2012, 12:84

54. Hungria M, Franco A, Sprent J: New sources of high-temperature tolerant rhizobia for Phaseolus vulgaris L. Plant and Soil 1993, 149(1):103-109.

55. Dominguez-Ferreras A, Perez-Arnedo R, Becker A, Olivares J, Soto MJ, Sanjuan J: Transcriptome profiling reveals the importance of plasmid pSymB for osmoadaptation of Sinorhizobium meliloti. J Bacteriol 2006, 188(21):7617-7625.

56. Goloubinoff P, Mogk A, Zvi AP, Tomoyasu T, Bukau B: Sequential mechanism of solubilization and refolding of stable protein aggregates by a bichaperone network. Proc Natl Acad Sci U S A 1999, 96(24):13732-13737

57. Han $Y$, Zhou D, Pang $X$, Zhang L, Song $Y$, Tong Z, Bao J, Dai E, Wang J, Guo Z, Zhai J, Du Z, Wang X, Huang P, Yang R: Comparative transcriptome analysis of Yersinia pestis in response to hyperosmotic and high-salinity stress. Res Microbiol 2005, 156(3):403-415.

58. Oliveira LR, Marcelino FC, Barcellos FG, Rodrigues EP, Megias M, Hungria M: The nodC, nodG, and glgX genes of Rhizobium tropici strain PRF 81. Funct Integr Genomics 2010, 10(3):425-431.

59. Van Laere A: Trehalose, reserve and/or stress metabolite? FEMS Microbiology Letters 1989, 63(3):201-209.

60. McIntyre HJ, Davies H, Hore TA, Miller SH, Dufour JP, Ronson CW: Trehalose biosynthesis in Rhizobium leguminosarum bv. trifolii and its role in desiccation tolerance. Appl Environ Microbiol 2007, 73(12):3984-3992.
61. Bernard T, Pocard J-A, Perround B, Le Rudulier D: Variations in the response of salt-stressed Rhizobium strains to betaines. Archives of Microbiology 1986, 143(4):359-364

62. Cascales E, Christie PJ: The versatile bacterial type IV secretion systems. Nat Rev Microbiol 2003, 1(2):137-149.

63. Fronzes R, Christie PJ, Waksman G: The structural biology of type IV secretion systems. Nat Rev Microbiol 2009, 7(10):703-714

64. Holland IB, Schmitt L, Young J: Type 1 protein secretion in bacteria, the ABC-transporter dependent pathway (review). Mol Membr Biol 2005, 22(1-2):29-39.

65. Pimenta AL, Racher K, Jamieson L, Blight MA, Holland IB: Mutations in HlyD, part of the type 1 translocator for hemolysin secretion, affect the folding of the secreted toxin. J Bacteriol 2005, 187(21):7471-7480.

66. Sapriel G, Wandersman C, Delepelaire P: The $\mathbf{N}$ terminus of the HasA protein and the $\mathrm{Sec} B$ chaperone cooperate in the efficient targeting and secretion of HasA via the ATP-binding cassette transporter. J Biol Chem 2002, 277(8):6726-6732.

67. Wolff N, Sapriel G, Bodenreider C, Chaffotte A, Delepelaire P: Antifolding activity of the $\operatorname{Sec} B$ chaperone is essential for secretion of HasA, a quickly folding $A B C$ pathway substrate. J Biol Chem 2003, 278(40):38247-38253.

68. Wooldridge KG, Kizil M, Wells DB, Ala'aldeen DA: Unusual genetic organization of a functional type I protein secretion system in Neisseria meningitidis. Infect Immun 2005, 73(9):5554-5567.

69. Chang G: Multidrug resistance ABC transporters. FEBS Lett 2003, 555(1):102-105.

70. Doige CA, Ames GF: ATP-dependent transport systems in bacteria and humans: relevance to cystic fibrosis and multidrug resistance. Annu Rev Microbiol 1993, 47:291-319.

71. Walshaw DL, Poole PS: The general L-amino acid permease of Rhizobium leguminosarum is an $A B C$ uptake system that also influences efflux of solutes. Mol Microbiol 1996, 21(6):1239-1252.

72. Gouffi K, Pica N, Pichereau V, Blanco C: Disaccharides as a new class of nonaccumulated osmoprotectants for Sinorhizobium meliloti. Appl Environ Microbiol 1999, 65(4):1491-1500.

73. Fujihara S, Yoneyama T: Effects of $\mathrm{pH}$ and Osmotic Stress on Cellular Polyamine Contents in the Soybean Rhizobia Rhizobium fredii P220 and Bradyrhizobium japonicum A1017. Appl Environ Microbio/ 1993, 59(4):1104-1109.

74. Shamseldin A, Nyalwidhe J, Werner D: A proteomic approach towards the analysis of salt tolerance in Rhizobium etli and Sinorhizobium meliloti strains. Curr Microbiol 2006, 52(5):333-339.

75. Nakahigashi K, Yanagi H, Yura T: Regulatory conservation and divergence of sigma32 homologs from gram-negative bacteria: Serratia marcescens, Proteus mirabilis, Pseudomonas aeruginosa, and Agrobacterium tumefaciens. J Bacteriol 1998, 180(9):2402-2408.

76. Morita M, Kanemori M, Yanagi H, Yura T: Heat-induced synthesis of sigma32 in Escherichia coli: structural and functional dissection of $\mathrm{rpoH}$ mRNA secondary structure. J Bacteriol 1999, 181(2):401-410.

77. Nocker A, Hausherr T, Balsiger S, Krstulovic NP, Hennecke H, Narberhaus F: A mRNA-based thermosensor controls expression of rhizobial heat shock genes. Nucleic Acids Res 2001, 29(23):4800-4807.

78. Schluter JP, Reinkensmeier J, Barnett MJ, Lang C, Krol E, Giegerich R, Long SR, Becker A: Global mapping of transcription start sites and promoter motifs in the symbiotic alpha-proteobacterium Sinorhizobium melilot 1021. BMC Genomics 2013, 14:156.

79. Green HA, Donohue TJ: Activity of Rhodobacter sphaeroides RpoHII, a second member of the heat shock sigma factor family. J Bacterio/ 2006, 188(16):5712-5721

80. Nuss AM, Glaeser J, Berghoff BA, Klug G: Overlapping alternative sigma factor regulons in the response to singlet oxygen in Rhodobacter sphaeroides. J Bacteriol 2010, 192(10):2613-2623.

81. Wade JT, Castro Roa D, Grainger DC, Hurd D, Busby SJ, Struhl K, Nudler E: Extensive functional overlap between sigma factors in Escherichia coli. Nat Struct Mol Biol 2006, 13(9):806-814.

82. Huerta AM, Francino MP, Morett E, Collado-Vides J: Selection for unequal densities of sigma70 promoter-like signals in different regions of large bacterial genomes. PLoS Genet 2006, 2(11):e185.

83. Gopalan V, Vioque A, Altman S: RNase P: variations and uses. J Biol Chem 2002, 277(9):6759-6762. 
84. Quinto C, de la Vega H, Flores M, Fernandez L, Ballado T, Soberon G, Palacios R: Reiteration of nitrogen fixation gene sequences in Rhizobium phaseoli. Nature 1982, 299(5885):724-726.

85. Noel KD, Sanchez A, Fernandez L, Leemans J, Cevallos MA: Rhizobium phaseoli symbiotic mutants with transposon Tn5 insertions. J Bacteriol 1984, 158(1):148-155.

86. Wicks RJ: RNA molecular weight determination by agarose gel electrophoresis using formaldehyde as denaturant: comparison of RNA and DNA molecular weight markers. Int J Biochem 1986, 18(3):277-278.

87. Pfaffl MW: A new mathematical model for relative quantification in realtime RT-PCR. Nucleic Acids Res 2001, 29(9):e45.

88. Anders $\mathrm{S}$, Huber W: Differential expression analysis for sequence count data. Genome Biol 2010, 11(10):R106.

89. Perkins TT, Kingsley RA, Fookes MC, Gardner PP, James KD, Yu L, Assefa SA, He M, Croucher NJ, Pickard DJ, Maskell DJ, Parkhill J, Choudhary J, Thomson NR, Dougan G: A strand-specific RNA-Seq analysis of the transcriptome of the typhoid bacillus Salmonella typhi. PLoS Genet 2009, 5(7):e1000569.

90. Dillies MA, Rau A, Aubert J, Hennequet-Antier C, Jeanmougin M, Servant N, Keime C, Marot G, Castel D, Estelle J, Guernec G, Jagla B, Jouneau L, Laloe D, Le Gall C, Schaeffer B, Le Crom S, Guedj M, Jaffrezic F: A comprehensive evaluation of normalization methods for Illumina high-throughput RNA sequencing data analysis. Brief Bioinform 2012, 14(6):671-683.

91. Oshlack A, Robinson MD, Young MD: From RNA-seq reads to differential expression results. Genome Biol 2010, 11(12):220.

92. Tarazona S, Garcia-Alcalde F, Dopazo J, Ferrer A, Conesa A: Differential expression in RNA-seq: a matter of depth. Genome Res 2011, 21(12):2213-2223.

doi:10.1186/1471-2164-15-770

Cite this article as: López-Leal et al:: RNA-Seq analysis of the multipartite genome of Rhizobium etli CE3 shows different replicon contributions under heat and saline shock. BMC Genomics 2014 15:770.

\section{Submit your next manuscript to BioMed Central and take full advantage of:}

- Convenient online submission

- Thorough peer review

- No space constraints or color figure charges

- Immediate publication on acceptance

- Inclusion in PubMed, CAS, Scopus and Google Scholar

- Research which is freely available for redistribution 